\title{
O Dever de Cooperação Internacional na Fundamentação dos Direitos Humanos
}

\section{The Duty of International Cooperation on Human Right's Grounding}

\author{
Ademar Pozzatti Junior ${ }^{1}$ \\ ${ }^{1}$ Universidade Federal de Santa Maria (UFSM), Santa Maria, RS, Brasil
}

\begin{abstract}
Resumo: A presente pesquisa investiga se existe um dever de cooperação internacional no âmbito da fundamentação dos direitos humanos ou se a colaboração é apenas um ato de cortesia entre os Estados. Este trabalho analisa a teoria dos direitos humanos para verificar se a partir do seu discurso e da sua prática podem despontar argumentos capazes de afirmar tal dever. Por isso, fará uso de uma abordagem normativa do tema. A hipótese deste trabalho é que tanto a fundamentação moral quanto a fundamentação jurídica dos direitos humanos impõem um dever de cooperação internacional. Para a construção desse argumento, primeiramente verifica-se como a própria ideia de direitos humanos se entrelaça com a ideia de cooperação internacional. Posteriormente, verifica-se a fundamentação moral e jurídica dos direitos humanos para entender como elas transportam o edifício ético da solidariedade em direção à ação política, na forma de cooperação internacional.
\end{abstract}

Palavras-chave: Direitos Humanos. Cooperação Internacional. Fundamentação Moral.

\begin{abstract}
The present research investigates if there is a duty of international cooperation on human rights' grounding or if international collaboration is only an act of courtesy between states. This paper analyses this duty in the human rights' theory in order to verify if its discourse and practice can build arguments capable of affirming that duty. Therefore, it will use a normative approach to the theme. The hypothesis which guides this research is that both moral and legal grounding of human rights impose an international cooperation obligation. In order to build this argument, firstly if verified how the idea of human rights is related to the idea of international cooperation is. Then, moral and legal grounding of human rights are investigated in order to understand how they can convert the ethical building of solidarity in to political action, in the shape of international cooperation.
\end{abstract}

Keywords: Human Rights. International Cooperation. Moral Grounding.

Recebido em: 18/10/2018

Revisado em: 25/10/18

Aprovado em: 09/09/19 


\section{Introdução}

A globalização pode ser analisada sob inúmeros aspectos, todos eles relacionados à transformação dos ambientes nacionais em esferas globais. Assim, temas que antes eram pensados sob uma ótica estritamente nacional passam à escala mundial, modificando por completo a dinâmica das relações políticas, econômicas, sociais, e também jurídicas a eles relacionados (SIMMONS, 2009). A realidade atual já não enxerga, portanto, o Estado nacional como quintessência da organização social e política e como limitador das relações internacionais.

A partir do século XIX, com o desenvolvimento tecnológico e o incremento da mobilidade humana, se desenvolveu uma sociedade interconectada, baseada em redes locais, regionais e globais de relacionamento (CASTELLS, 2005, p. 25). Diante desse novo cenário, despontaram questões transversais - como a promoção e a tutela dos direitos humanos - que passaram a exigir atuação conjunta das instituições estatais para o seu tratamento (SIMMONS, 2009). Isso não seria um problema se o direito e a estrutura institucional do Estado tivessem se internacionalizado na mesma medida em que os fatos sociais. Mas em que pese as fronteiras geográficas estejam cada vez mais ligadas a aspectos meramente simbólicos, ainda existem temas da agenda contemporânea cuja atuação transnacional é eivada de obstáculos em virtude, dentre outros aspectos, do descompasso entre a lógica de ação institucional e a realidade social.

Em trabalho desenvolvido em 2017, investigou-se a existência de um fundamento para afirmar a existência de um dever de cooperação internacional na teoria moral deontológica da tradição kantiana para mostrar que a sua concepção da razão prática impõe um dever de cooperação internacional (POZZATTI, 2017). Para afirmar que a cooperação internacional não era um mero ato de cortesia dos Estados, mas um dever, verificou-se que “[...] é possível transpor o edifício ético kantiano para as relações internacionais através do desenvolvimento de um cosmopolitismo moral e jurídico" (POZZATTI, 2017, p. 621). Dando sequência à pesquisa, neste trabalho quer-se investigar em que medida existe um dever de cooperação internacional amparado na fundamentação dos direitos 
humanos. Para tanto, será realizada a uma abordagem normativa do tema capaz de afirmar tal dever.

A opção pelos direitos humanos para buscar lastrear o dever de cooperação se deve ao fato de que em nossos dias eles se tornaram tão abrangentes que qualquer problema social pode ser abordado a partir da sua ótica. Dessa forma, a cooperação internacional também é um fenômeno para o qual o discurso dos direitos humanos pode ser invocado, sobretudo no espectro de países de modernidade tardia, em que a cooperação internacional muitas vezes funciona como uma garantia para a implementação de direitos humanos (TORRONTEGUY, 2010). Nesse sentido, pretende-se buscar na teoria dos direitos humanos uma compreensão do princípio da solidariedade que permita abranger o conteúdo material do discurso da cooperação internacional. Essa compreensão permite inferir que a cooperação exerce a função de meio para a efetivação de direitos.

Nessa perspectiva, o objetivo deste trabalho é examinar de que forma a gramática dos direitos humanos pode ser utilizada para fundamentar um dever de cooperação internacional entre os Estados. Para tanto, na primeira parte será investigado a maneira com que o conceito de direitos humanos se entrelaça com a própria ideia de cooperação internacional. Na segunda parte serão discutidas as possibilidades e aporias de uma fundamentação para os direitos humanos, tanto na perspectiva moral quanto na perspectiva jurídico-política. Na terceira parte será verificado como a fundamentação moral dos direitos humanos se desdobra no princípio ético da solidariedade e como a sua fundamentação jurídico-política lastreia a cooperação internacional nos tratados internacionais.

\section{A Cooperação Internacional na Construção do Discurso dos Direitos Humanos}

Segundo Norberto Bobbio (2005, p. 50), os direitos humanos nascem como direitos naturais universais, desenvolvem-se como direitos positivos particulares, para finalmente encontrarem sua plena realização como direitos positivos universais. Assim, a Declaração Universal dos Direitos Humanos, de 1948, representaria a síntese de um movimento 
dialético, que começa pela universalidade abstrata dos direitos naturais, transforma-se na territorialidade concreta dos direitos estatais, e termina na universalidade concreta do direito internacional dos direitos humanos. No entanto, em países de modernidade tardia, onde a etapa da "territorialidade concreta" dos direitos humanos nunca foi superada, a sua agenda coexiste com a "universalidade do direito internacional dos direitos humanos", de forma que a cooperação internacional se apresenta como um instrumento capaz de tornar uma, a continuidade da outra.

Segundo Marie-Bénédicte Dambour (2010), os direitos humanos foram objeto de diversas teorias de conceituação e fundamentação ao longo dos séculos. Tendo sido conhecidos como direitos naturais até o século XVIII, os mesmos direitos foram chamados de direitos públicos subjetivos no século XIX e finalmente convertidos em direitos humanos e fundamentais a partir da segunda metade do século XX. Esses sucessivos conceitos se devem às sucessivas tentativas de fundamentar os direitos humanos em cada momento histórico, conferindo-lhes finalidade e significado, e traçando metas para a sua promoção e proteção (BOBBIO, 2004, p. 21).

Entretanto, foi só após a segunda guerra mundial que o discurso dos direitos humanos se tornou um tema inescapável ao debate jurídico e à prática política. Esse movimento começou diante da "negação do valor da pessoa humana como valor e fonte do direito", quando passou a emergir "[...] a necessidade de reconstrução dos direitos humanos, como referencial e paradigma ético que aproxime o Direito da Moral" (PIOVESAN, 2011, p. 129).

A exclusão e a descartabilidade de pessoas humanas, experimentada ao longo dos regimes totalitários da primeira metade do século XX, funcionou como um terreno fértil e propício para a emergência de inúmeros princípios e valores, encabeçados pela defesa da dignidade humana, princípio este que é o verdadeiro fundamento dos direitos humanos para as teorias transcendentalistas (BOBBIO, 2004). Deontologicamente, reconhecer os direitos humanos como tendo por base a dignidade da pessoa humana - que é universal - é reconhecer a existência de direitos ao homem independentemente de ele ser cidadão de um determinado Estado 
(COMPARATO, 2001). Mas ontologicamente, o Estado solipsista exige do internacionalista que se compreenda como a sua estrutura institucional pode ser ressignificada para que nela caiba a realização dos direitos humanos (MORAVCSIK, 2000, p. 218). Nessa perspectiva, a cooperação internacional é uma estratégia útil para aproximar o que se é, do que devemos ser - ou do que podemos ser.

Os momentos em que a dignidade humana não foi respeitada foram momentos em que inúmeros indivíduos foram privados do direito a ter direitos. Vale lembrar que a dinâmica do totalitarismo nazista, cuja característica principal foi a permissibilidade absoluta, tinha como pressuposto a ideia de que os seres humanos eram supérfluos, podendo, por isso, serem descartados sem qualquer consideração por valor algum que lhes fosse intrínseco (ARENDT, 1998, p. 480). Assim, o totalitarismo despiu o ser humano de todo valor, havendo uma verdadeira "coisificação" do ser humano, utilizado como meio para a obtenção dos fins objetivados pelo regime nazista. Nesse sentido, a experiência totalitária promoveu uma verdadeira ruptura com a evolução histórica do garantismo que vinha até então se desenvolvendo, sendo necessário após ele, uma autêntica reconstrução dos direitos humanos (LAFER, 1988, p. 153).

Na perspectiva de Hannah Arendt, o totalitarismo, o antissemitismo e o imperialismo do século XX influenciaram o processo de amadurecimento da ideia de dignidade humana como fundamento do direito internacional dos direitos humanos. Segundo a autora, estes eventos demonstraram que a dignidade humana precisa de nova garantia,

[...] somente encontrável em novos princípios políticos e em uma nova lei na terra, cuja vigência desta vez alcance toda a humanidade, mas cujo poder deve permanecer estritamente limitado, estabelecido e controlado por entidades territoriais novamente definidas. (ARENDT, 1988, p. 12)

No entendimento de Hannah Arendt, não há liberdade quando não se faz a devida identificação do ser humano como sujeito das normas e leis sociais, quando não se realiza uma verdadeira política capaz de concretizar a dignidade humana no espaço público e quando não é permitido 
ao ser humano construir-se publicamente junto com seus pares. Segundo Arendt (1998, p. 383), “[...] "o simples fato da existência vincula o homem, a mulher e a criança à ordem jurídica internacional". Essa é a "novidade" do direito internacional dos direitos humanos: o ser humano passa a ser sujeito de direito na ordem internacional. Tal fato amplia o espaço público, pressuposto do exercício da liberdade, que não está mais reduzido ao espaço "cidade-estado" dos gregos, mas o amplia para o espaço do mundo (ARENDT, 1998, p. 383).

Dessa forma, os direitos humanos, inspirados na ideia de soberania popular, seriam verdadeiros diques de resistência às arbitrariedades dos regimes particulares que se amparavam na ideia de soberania estatal. Entretanto, o nacionalismo, que se constitui na ideia central da construção e sedimentação dos Estados-nacionais a partir da modernidade, acabou por dificultar a objetivação dos direitos humanos, que tinham como condição a sua necessária universalidade (MORAVCSIK, 2000). Esse mesmo nacionalismo que obstaculiza a materialização dos direitos humanos, se transforma no maior empecilho para a operacionalização da cooperação internacional, como será visto mais adiante.

Da própria ideia de dignidade humana advêm as características dos direitos humanos. Essas características podem emprestar argumentos ao entendimento de que existe um dever de cooperação internacional entre os Estados. Segundo André de Carvalho Ramos, dentre os muitos atributos dos direitos humanos estariam a universalidade (caráter erga omnes dos direitos humanos), a indivisibilidade, a interdependência, a irrenunciabilidade, a imprescritibilidade, a inalienabilidade, a sua aplicabilidade imediata e o fato de serem abertos, ou seja, não estando limitados aos direitos já positivados (RAMOS, 2005, p. 163).

Para fins da argumentação proposta nesse trabalho, qual seja, de que os direitos humanos podem ser um fundamento para afirmar um dever de cooperação internacional, cabe atentar sobretudo à dimensão espacial da universalidade dos direitos humanos. Nessa perspectiva, os direitos humanos têm como nota fundamental a sua internacionalização, ou seja, seu reconhecimento em todas as partes do mundo. Justamente por isso é obje- 
to de muitas críticas, que o acusam de imperialismo cultural (DONNELY, 1984; JOUANNET, 2012, p. 110).

Tendo os direitos humanos um conteúdo universal, eles extrapolam o poder normativo dos Estados nacionais, podendo servir de lastro para a ideia de cooperação internacional sob três perspectivas. A primeira é ontológica, já que os direitos humanos exigem a cooperação internacional devido a sua própria definição. Isso se deve ao fato de que a cooperação internacional se impõe justamente para garantir o caráter indissociável e interdependente dos direitos humanos espacialmente, sendo, portanto, um instrumento para defender a própria ideia de direitos humanos. Assim, a cooperação internacional se impõe como consequência do próprio conceito dos direitos humanos, como verdadeiro componente da compreensão dos direitos humanos que ela é. Em uma frase: como os direitos humanos são universais, indissociáveis e interdependentes, a ideia de cooperação internacional faz parte da sua própria definição.

A segunda perspectiva é deontológica e se constrói a parir da ideia de que, como os direitos humanos existem em "todos" os lugares, eles devem ser efetivados em todos os lugares. Ora, se os direitos humanos, por serem universais, estabelecem deveres (e impõem limites) a todos os Estados, os Estados mesmos devem cooperar para a persecução desses direitos, que em última ratio, são direitos humanos.

A terceira perspectiva é a da práxis, e se refere à universalidade concreta, e não abstrata, dos direitos humanos (POZZATTI; HAAG, 2017). Justamente porque os direitos humanos querem encontrar os indivíduos construídos socialmente, para os quais cada direito humano tem um significado diferente, uma das principais condições para a universalidade é a pluralidade de interpretações (DONNELY, 1984). A cooperação internacional faz com que as instituições do aparelho estatal absorvam outras interpretações - ou pelo menos descubram que elas existem - de forma que se estabelece como uma via de universalização daqueles direitos que estão postos nas cartas como devendo ser universais, mas que na prática ainda estão caminhando para serem. É nesse sentido que a cooperação tem grande margem de ação na transformação do nacionalismo em algo mais plural de uma maneira muito delicada. 
Ainda que seja possível a ligação entre direitos humanos e cooperação, esta não é um dado perfeito, alheio a obstáculos. A própria fundamentação dos direitos humanos, mesmo separada da ideia de um dever de cooperar, apresenta além das possibilidades, certas falhas. Frente a isso, cabe uma análise dos tipos de incentivos e obstáculos que essas representam para a fundamentação não apenas dos direitos humanos, mas também em sua relação com a cooperação internacional.

\section{Possibilidades e Aporias da Fundamentação dos Direitos Humanos}

O tema dos direitos humanos tem sido amplamente debatido por acadêmicos das mais diversas matrizes (DAMBOUR, 2010, p. 2). Debates esses que buscam responder o que são os direitos humanos? E quais são os seus fundamentos? Para fins de amparar o dever de cooperação internacional no âmbito dos direitos humanos, é necessário responder tais questões.

Ao falar da fundamentação dos direitos humanos, fica implícito falar das razões para reconhecer esses direitos. Essas razões podem ser de ordem moral ou jurídica. A primeira estratégia é a fundamentação moral dos direitos humanos universais, sendo que existem autores que negam (PINZANI, 2010) e outros que afirmam (COMPARATO, 2006) tal possibilidade. Por outro lado, a fundamentação jurídica dos direitos humanos pode se dar em dois níveis: estatal (HABERMAS, 2007) e internacional (HABERMAS, 1992; 2012; 2014), se for entendido que os direitos humanos só existem como direitos fundamentais positivados nas constituições estatais ou se for reconhecida a existência de uma verdadeira e propriamente dita ordem jurídica internacional.

São tantos os debates advindos do embasamento dos direitos humanos e poucas as soluções, a ponto de Norberto Bobbio (2004, p. 24) ter proposto o deslocamento do eixo de preocupação da sua fundamentação para a sua implementação, de forma que "[...] o problema teria deixado de ser essencialmente filosófico para se tornar principalmente político". Entretanto, Bobbio parecia negligenciar que o problema político da im- 
plementação dos direitos humanos depende também da resposta que se dá a questão da sua fundamentação, pois dessas respostas derivariam consequências políticas concretas (PINZANI, 2010, p. 28). No âmbito da cooperação internacional, por exemplo, só haveria um dever de cooperação internacional para com os países que não firmaram tratados internacionais se fosse considerada a dimensão moral dos direitos humanos. Enquanto fosse considerada somente a dimensão jurídica dos direitos humanos, haveria apenas o dever de cooperação internacional entre Estados enlaçados por legislação.

Justamente para amparar essas consequências políticas concretas, cumpre saber se os direitos humanos são direito, no sentido estrito do termo, ou se são apelos morais. Aqueles que valorizam mais o elemento "humano" do termo "direitos humanos" advogam a existência de uma fundamentação moral, portanto absoluta e universal, para tais direitos. Por outro lado, existem os que entendem inexistir qualquer fundamento último para os direitos humanos universais, sendo que só caberia falar em "direitos humanos" quando eles fossem positivados em uma ordem jurídica em sentido estrito, caracterizada pela legitimidade e pela coatividade (HABERMAS, 2012, p. 6).

$\mathrm{Na}$ tentativa de encontrar as bases morais para fundamentar a existência de direitos humanos, Pinzani sintetiza diversas estratégias para a fundamentação de tais direitos. As primeiras estratégias seriam as religiosas, que "fundamentam os direitos humanos em um apelo para a origem divina do homem". Segundo Pinzani, estas estratégias falham por pressupor uma razão baseada na subjetividade, na fé de cada um, para a construção de um argumento que se propõe de validade universal. A segunda estratégia é a antropológica, para a qual "a existência dos direitos humanos seria derivada de certas características essenciais dos seres humanos". Pinzani diz que essa estratégia é falha porque essas características dificilmente podem ser provadas. A terceira estratégia é a transcendental, que atribuiria aos “[...] direitos humanos a qualidade de pressupostos necessários para o agir humano [...]" e os fundaria na razão. Entretanto, Pinzani (2010, p. 29) afirma que essa estratégia é bastante restrita quanto aos direitos que ela poderia fundamentar. 
Assim, Alessandro Pinzani (2010, p. 42) aduz a inexistência de um fundamento moral absoluto para sedimentar os direitos humanos universais, de forma que eles só poderiam ser considerados normas jurídicas. Nas suas palavras: "só privando a ideia de direitos humanos de todo caráter moral se torna de fato possível fundamentar tais direitos".

A partir da impossibilidade de construir uma resposta absoluta para a busca de fundamentos morais para os direitos humanos, cabe encontrar argumentos jurídicos. Restaria saber, então, se esses direitos são fundamentados nas ordens jurídicas estatais ou se são fundamentados em uma ordem jurídica internacional, sendo, portanto, verdadeiramente universais (MORAVCSIK, 2000). A típica tese positivista escolhe a primeira opção, visto que

[...] direitos humanos não positivos não seriam direitos verdadeiramente, mas no máximo exigências morais ou até simples apelos. Só direitos positivos, é dizer, direitos garantidos no âmbito de uma certa comunidade jurídica a certos indivíduos, podem ser chamados corretamente de direitos. (PINZANI, 2010, p. 41)

Segundo essa lógica, já que não há uma comunidade jurídica global que compreenda todos os seres humanos e já que, portanto, não há direitos positivos que podem ser atribuídos a todos os seres humanos e em qualquer lugar do mundo, não há direitos humanos no sentido mais próprio do termo.

Assim, para Pinzani, além de não existir uma justificação moral para os direitos humanos, não haveria também uma justificação jurídica para tais direitos no plano internacional. Uma posição parecida é defendida por Jürgen Habermas (2001, p. 170), para quem “[...] os direitos humanos universais, assim como as normas morais, se referem a todos os seres humanos, mas na sua qualidade de normas jurídicas só protegem indivíduos como membros de uma certa comunidade jurídica".

Essa é a cara de Janus dos direitos humanos, só que ao invés de ter uma cara voltada para a paz e outra para a guerra, como o deus romano, os direitos humanos tem uma cara voltada para a moral e outra cara voltada para a política. Ora, nessa perspectiva, os direitos humanos universais 
só diriam respeito a todas as pessoas como normas morais, mas na qualidade de normas jurídicas que são, só diriam respeito aos cidadãos de um Estado (HABERMAS, 2001, p. 171).

O fato de os direitos humanos serem preceitos jurídicos, não impediria a possibilidade de buscar sua fundamentação filosófica. Para Jürgen Habermas (1997, p. 140), a existência de uma relação entre princípios morais e direitos humanos "[...] não é de todo falsa, pois uma ordem jurídica só pode ser legítima, quando não contrariar princípios morais".

Para Habermas (2001, p. 144), o direito “[...] reclama não apenas aceitação; ele demanda dos seus endereçados não apenas um reconhecimento fático, mas antes reivindica 'merecer' o reconhecimento". Habermas ratifica que, através dos componentes de legitimidade da validade jurídica, o direito adquire uma relação com a moral - aquele tem a sua legitimidade derivada desta. A tensão entre a positividade do direito e sua pretensão de legitimidade está latente no próprio direito.

Um estudo mais atento da obra de Habermas vai perceber uma aparente ambiguidade nas suas posições. Na obra Faticidade e Validade, originalmente de 1992, ele sugere que os direitos humanos universais não seriam "direito" e sim "apelos morais", e somente seriam "direito" quando fossem incorporadas, ou "positivadas" pelos Estados. Essa é justamente a posição de Hans Kelsen que, em seu comentário à Declaração Universal dos Direitos Humanos da ONU, de 1948, considerou-a uma simples recomendação, um "[...] apelo às nações que não possuiria valor jurídico até a sua positivação” (KELSEN, 1950, p. 39).

Entretanto, Habermas parece ter atualizado o seu posicionamento nas obras mais recentes. Se em Direito e Democracia ele não se dedicou à fundamentação moral dos direitos humanos, mas somente a sua reconstrução político-jurídica, nas obras mais recentes Habermas (2012a, p. 132) aponta tanto para a sua fundamentação moral quanto jurídica, agora como pertencente a "uma ordem mundial". Nessa nova perspectiva, os direitos humanos universais estão sujeitos às mesmas regras do direito positivo moderno, tendo aplicabilidade internacional não por conta de uma concepção moral - pré-política ou até mesmo metafísica - mas, sim, por dar execução e cumprimento ao próprio ordenamento jurídico positiva- 
do (HABERMAS, 2012a, p. 175). A evolução do seu pensamento está no fato de que ele passou a reconhecer uma verdadeira juridificação das relações internacionais capaz de impor restrições à vontade dos Estados.

Na obra Sobre a constituição da Europa, Habermas encontra um fundamento moral para os direitos humanos universais: a dignidade humana. Nas suas palavras,

[...] a dignidade humana não é uma expressão classificatória posterior, ou uma espécie de simulacro por detrás do qual se esconde uma multiplicidade de fenômenos diferentes, mas sim a fonte moral da qual os direitos humanos extraem seu conteúdo. (HABERMAS, 2012b, p. 11)

Dessa forma, "[...] a origem dos direitos humanos a partir da fonte moral da dignidade humana explica a força política explosiva de uma utopia concreta" (HABERMAS, 2012b, p. 11). E conclui o autor:

[...] os direitos humanos formam uma utopia realista na medida em que não mais projetam a imagem declarada da utopia social de uma felicidade coletiva; antes, eles ancoram o próprio objetivo ideal de uma sociedade justa nas instituições de um Estado constitucional. (HABERMAS, 2012b, p. 31)

A evolução da filosofia habermasiana então se dá no sentido de entender que é possível haver uma justificação moral para a existência dos direitos humanos universais, o que não acontecia nas obras anteriores. Agora,

[...] os direitos humanos circunscrevem precisamente a parte de uma moral esclarecida que pode ser traduzida no medium do direito coercitivo e ter realidade política efetiva na robusta configuração de direitos fundamentais efetivos. (HABERMAS, 2012b, p. 19)

Junto com o reconhecimento de uma justificação moral, Habermas permanece defendendo que os direitos humanos como normas jurídicas ainda permanecem bastante vinculadas ao "Estado constitucional". Ele 
não nega aqui a existência de direitos humanos universais, no sentido jurídico. Ele apenas reconhece que a ordem jurídica internacional ainda é embrionária, mas já está dando o "[...] passo decisivo no caminho para uma sociedade mundial constituída politicamente" (HABERMAS, 2012b, p. 40).

Mesmo que se entendesse que os direitos humanos universais não seriam direito no sentido autêntico do termo, isso não implicaria que a função dos direitos humanos ficaria esvaziada (KENNEDY, 2002, p. 121). Para os defensores dessa posição, os direitos humanos inspiram as cartas constitucionais, tornando-se verdadeiros critérios de legitimidade dessas ordens jurídicas (HAFNER-BURTON, 2013). A potência do discurso dos direitos humanos estaria exatamente no fato de que eles representariam critérios de legitimação: "são direitos subjetivos que cada ordem jurídica deve garantir aos seus membros se ela quer ser legítima" (PINZANI, 2010, p. 45). Em outras palavras: a legitimidade de uma ordem jurídica pode ser averiguada na medida em que ela garanta e respeite tais direitos - e isso não se refere apenas a sua positivação, mas à operacionalização dos mesmos, o que, frequentemente, envolve a cooperação internacional (TORRONTOGUY, 2010).

Entretanto, com Habermas, há que se reconhecer um adensamento de juridicidade do direito internacional e dos direitos humanos, pois ambos caminham para uma positivação jurídica legítima e execução judicial fática. Assim, os direitos humanos são os elementos fundantes do processo de constitucionalização do direito internacional, já que quando os Estados se inserem às Nações Unidas pactuam o compromisso de sua defesa e implementação, ao mesmo tempo que que pactuam o compromisso com a cooperação internacional. Do ponto de vista institucional, "[...] a cooperação internacional como dever legal não se baseou no direito consuetudinário internacional, mas derivou das obrigações contratuais contidas no direito internacional positivo [...]" de matriz onusiana (WOLFRUM, 1986, p. 194).

Assim, por existir uma ordem jurídica internacional "em formação", ao lado das ordens jurídicas estatais (DELMAS-MARTY, 2006; KOSKENNIEMI, 2001), considerando a sua capacidade normativa e o 
poder executório, os direitos humanos impõem restrição e limitam o conceito clássico de soberania, constituindo a base de uma solidariedade universal.

De qualquer forma, mesmo admitindo-se que não existisse o direito internacional (no sentido jurídico do termo), os direitos humanos expressos nas cartas internacionais continuariam existindo independentemente do rótulo que tivessem, e seriam operacionalizados quando fossem positivados no âmbito das constituições estatais, se transfigurando em direitos fundamentais.

Assim, duas questões se apresentam para esse estudo. Se forem considerados os direitos humanos como normas morais, e não jurídicas, é possível afirmar um dever de cooperação internacional de ordem moral. Entretanto, se forem considerados os direitos humanos como normas jurídicas, cabe buscar o dever de cooperação internacional na própria legislação. Não se tratam de abordagens contraditórias e muito menos excludentes, mas sendo que os direitos humanos têm uma cara de Janus, cumpre entendê-los sob essa dupla perspectiva.

\section{A Dupla Fundamentação do Dever de Cooperação Internacional no Quadro dos Direitos Humanos: moral e política}

Nessa parte do trabalho, serão abordadas as duas possibilidades de fundamentação dos direitos humanos e verificadas as suas respectivas consequências na afirmação de um dever de cooperação internacional. Primeiramente será investigada a estratégia de fundamentação moral dos direitos humanos (4.1) e posteriormente será vista a estratégia de fundamentação político-jurídica desse dever (4.2).

\subsection{Direitos Humanos como Materialização do Princípio Ético da Solidariedade}

A primeira tentativa de fundamentação dos direitos humanos universais, como normas morais, é aquela que se dá a partir da tradição 
kantiana da razão prática. Assim, essa corrente de pensamento sustenta que "[...] a busca dos princípios norteadores dos direitos humanos seguiria ainda a clausura moral determinada pelo pensamento kantiano." (POZZATTI, 2017, p. 619).

Mais do que ainda, sobretudo a partir das guerras mundiais, das guerras coloniais e da guerra fria do século XX, parece estar mais forte do que nunca a reivindicações para que os Estados nacionais também ajam de forma ética, rompendo com a tradição maquiavélica da separação entre moral e política. Nesse contexto, marcado por inúmeras violações de direitos, tornou-se necessário construir toda uma normatividade internacional, a fim de resguardar e proteger esses direitos, até então inexistentes. Os Estados foram obrigados a fazer com que o respeito aos direitos humanos encontrasse efetiva proteção, senão porque (in)existia uma verdadeira ordem jurídica internacional, porque esses direitos humanos se transformaram em verdadeiros critérios de legitimação dos ordenamentos jurídicos estatais.

Justamente por isso, o grande impacto da vertente kantiana do direito se concretizou com a emergência do direito internacional dos direitos humanos. Por isso, é importante entender o ideal de cooperação internacional no âmbito desse discurso.

$\mathrm{Na}$ esteira de Kant, Fábio Konder Comparato (2004, p. 26) afirma que "[...] os direitos humanos foram identificados com os valores mais importantes da convivência humana, aqueles sem os quais a sociedade acaba perecendo, fatalmente, por um processo irreversível de desagregação". A tutela jurídica dos direitos humanos seria, portanto, a proteção dos valores mais caros à humanidade, ou seja, representam a consciência ética coletiva de toda a humanidade. Daí vem a universalidade dos direitos humanos.

Diante desse quadro, propõe-se interpretar a cooperação internacional como prática de um desses princípios éticos: a solidariedade. Para tanto, partir-se-á da sistematização dos princípios éticos propostas por Fábio Konder Comparato para explicar a cooperação na sua dimensão primeira - a solidariedade. 
Antes, é necessário esclarecer que princípio tem a conotação estabelecida por Robert Alexy (1997, p. 81). Trata-se de uma norma jurídica que tem formato de um "[...] mandamento de otimização que deve ser perseguido dentro da maior possibilidade fática e jurídica possível [...]”, diferentemente das regras, que também sendo uma espécie normativa, deve ser aplicada dentro do esquema tudo ou nada. Justamente nesses termos os princípios éticos traduzem aspirações humanas inalcançáveis em sua plenitude, mas permanentemente buscadas. Tais princípios são, por isso, mandamentos de otimização, “[...] estão no campo do dever ser e são balizas para todo o ordenamento jurídico.” (COMPARATO, 2006, p. 511).

Conforme mostram os ensinamentos de Comparato, os princípios éticos podem ser sistematizados em três níveis. No primeiro nível está a dignidade da pessoa humana, que seria o "valor maior da convivência humana”. No segundo nível estão os princípios da verdade, justiça e amor. Por fim, para a realização desses, são exigidos outros quatro princípios que compõe o terceiro nível: liberdade, igualdade, segurança e solidariedade. Tanto os níveis quanto os princípios estão interconectados, pois "[...] os valores superiores abrangem os inferiores, que existem como especificações daqueles.” (COMPARATO, 2006, p. 509).

O primeiro princípio ético é o da dignidade da pessoa humana, que teve um papel decisivo para a formação do debate acerca dos direitos humanos. É importante perceber que a Declaração Universal dos Direitos Humanos da ONU de 1948, no seu preâmbulo afirma que "[...] o reconhecimento da dignidade inerente a todos os membros da família humana e de seus direitos iguais e inalienáveis". O artigo $1^{\circ}$ dispõe que "Todos os seres humanos nascem livres e iguais em dignidade e em direitos". Dessa forma, a noção de "dignidade" é o cerne deste processo porque ele se torna a marca de que esta parte da humanidade merece respeito e reconhecimento (JOUANNET, 2012, p. 111).

Esses princípios éticos foram inscritos ao longo dos tempos no cerne das preocupações e problemas com as quais a humanidade se deparou. $\mathrm{Na}$ obra de Comparato eles assumem uma dimensão constitutiva de um "programa ético", algo imprescindível para a "dignidade da pessoa humana" no mundo contemporâneo. Assim sendo, tais princípios deverão 
servir de base à fundação da "sociedade universal do gênero humano", conforme salienta Comparato. Já na antiguidade o estoicismo sustentou a unidade moral do homem e a dignidade humana. Entretanto foi somente no iluminismo que Immanuel Kant sustentou que o ser humano, por sua racionalidade, é um fim em si mesmo, sendo inadmissível considerá-lo meio para qualquer outro fim (COMPARATO, 2004, p. 20). A vida humana, dessa maneira, não deve se preocupar com qualquer outra função que não a sua preservação e dignidade.

Aqui se encaixa a distinção kantiana entre as pessoas e as coisas, segundo a qual as coisas estão à disposição dos seres humanos para que eles concretizem os fins delineados por suas vontades racionais. Assim, enquanto as coisas são meio, as pessoas são fim em si mesmas. Além de ser um fim em si próprio, o ser humano, por sua racionalidade, é dotado de autonomia para conduzir a sua vida e tomar as suas decisões. Essa racionalidade exige que cada um aja de modo que suas ações sejam aplicáveis por todos, que ninguém aja de modo a prejudicar outrem e que cada um colabore com a busca da felicidade do outro (COMPARATO, 2004, p. 21).

Nesse sentido, é promovida uma oposição ética entre coisas e pessoas. As coisas possuem um valor relativo, enquanto a pessoa humana possui um valor absoluto (dignidade). Essa premissa kantiana é fundamental para o programa ético de Comparato, já que advoga pela liberdade da pessoa humana (COMPARATO, 2006, p. 458). A dignidade da pessoa está ligada à sua capacidade de agir livremente, elegendo seus planos e seus fins.

Segundo Comparato (2006, p. 522), a dignidade especifica-se em alguns princípios cardeais: verdade, justiça e amor. A verdade se refere tanto ao saber racional que influenciou todo o saber científico e a racionalidade ocidental, mas também se refere a um juízo crítico no sentido de preservar a dignidade humana. A justiça, como distribuição proporcional às necessidades parte da desigualdade de fato entre os cidadãos, para estabelecer a igualdade de direito: os que possuem menos devem receber mais, quer dos outros, quer da coletividade (COMPARATO, 2006, p. 527). Já o amor se traduz como doação para com os outros e contribui para o constante aperfeiçoamento da justiça (COMPARATO, 2006, p. 533). 
Na perspectiva de Comparato, esse esquema ético contribui para que as relações humanas se tornem mais solidárias, de forma que a realização dos três princípios exige o princípio da solidariedade. Mais do que isso, a dignidade da pessoa humana, compreendida através da verdade, da justiça e do amor, exige quatro outros postulados éticos, "complementares aos primeiros, interdependentes e correlatos entre si”. Esses princípios são os da liberdade, da igualdade, da segurança e da solidariedade. A cooperação internacional, conforme será visto mais adiante, se coaduna com essa ideia de solidariedade.

A liberdade foi concebida como uma virtude política do homem na antiguidade, e como um escudo de proteção contra os desmandos do Estado na modernidade. Essa liberdade frente ao Estado coloca todos os homens em formal igualdade. Ocorre que em meio à desigualdade material em que os homens estão imersos, cabe ao Estado agir para "construir" a igualdade de todos (ou evitar a desigualdade extrema) e evitar a miséria de muitos às custas da bonança de outros (COMPARATO, 2006, p. 555): daí a necessidade de se pensar os direitos humanos de segunda geração (COMPARATO, 2006, p. 46).

Aqui não se trata de uma oposição ontológica entre liberdade e igualdade. Ora, se tutelamos a liberdade, não haverá igualdade (como sentimos nas consequências quotidianas do neoliberalismo), mas se tutelamos a igualdade às últimas consequências, não há liberdade (como experimentou-se na experiência do socialismo real). Trata-se de buscar um meio termo entre esses dois princípios, uma "ponderação", e na teoria de Comparato essa conjugação é auxiliada pelos dois outros princípios éticos: a segurança e a solidariedade.

A segurança não se esgota na sua dimensão individual, compreendendo também a sua dimensão social, e não deve ser buscada a qualquer custo, como um fim. A segurança se justifica quando utilizada para garantir a ação do Estado na tutela conjunta da igualdade e da liberdade. Justamente para evitar os desmandos da segurança, que facilmente acarretaria a supressão de direitos individuais e sociais, acabando com a liberdade, por exemplo, a segurança deve ser conjugada com o princípio da solida- 
riedade. Trata-se nas palavras de Comparato de uma "implicação recíproca" desses princípios éticos.

Assim, a partir da ideia kantiana, a solidariedade deve ser vista como um princípio ético. A solidariedade envolve a relativização dos interesses particulares em favor dos interesses coletivos. Trata-se da busca pelo bem comum, dos interesses de toda a sociedade, em nome dos quais deve-se promover a igualdade, a liberdade e a segurança. É justamente nesse sentido que Comparato se refere à solidariedade como o "fecho da abóbada" do edifício ético:

Ela é o fecho de abóbada do sistema de princípios éticos, pois complementa e aperfeiçoa a liberdade, a igualdade e a segurança. Enquanto a liberdade e a igualdade põem as pessoas umas diante das outras, a solidariedade as reúne, todas, no seio de uma mesma comunidade. Na perspectiva da igualdade e da liberdade, cada um reivindica o que lhe é próprio. No plano da solidariedade, todos são convocados a defender o que lhes é comum, quanto à segurança, ela só pode realizar-se em sua plenitude quando cada qual zela pelo bem de todos e a sociedade pelo bem de cada um dos seus membros. (COMPARATO, 2006, p. 577)

Ainda conforme alega Comparato, o princípio da solidariedade se efetiva a partir de três perspectivas: nacional, intergeneracional e internacional. Nacionalmente, a solidariedade se traduz nas mais diversas políticas públicas implementadoras dos direitos humanos de segunda geração nos chamados Estados democráticos e sociais. Intergeneracionalmente, o princípio ético da solidariedade está ligado à percepção de que todos os seres humanos são solidários com relação às futuras gerações e com o futuro do planeta (COMPARATO, 2006, p. 579).

Internacionalmente, a solidariedade vem se desenvolvendo a partir da criação de inúmeras organizações internacionais, como a Organização das Nações Unidas, que institucionalizam e impõem a cooperação (WOLFRUM, 1986). Essa dimensão do princípio da solidariedade fundamenta o ideal de cooperação internacional, para promover o desenvolvimento e também para implementar os direitos sociais que os Estados, 
sozinhos, são incapazes de garantir em seus territórios por questões estruturais, ou porque a própria demanda envolve elementos de conexão com outros Estados.

Assim, a cooperação internacional pode ser reconhecida como prática do princípio ético da solidariedade, para efetivação dos direitos humanos. Esse postulado permite afirmar um dever moral de cooperação internacional independentemente de tratados internacionais.

\subsection{Direitos Humanos como Prática Político-Jurídica}

Um dos argumentos que faz Bobbio descrente em relação a fundamentação moral dos direitos humanos é a sua historicidade, de forma que, se tais direitos fossem fundados na natureza humana, como preceitua Comparato, não haveria razão de terem sido historicamente construídos. A menos que considerássemos que a própria dignidade humana não fosse um valor absoluto, sendo ela mesma lapidada historicamente.

No dizer de Hannah Arendt (1998, p. 388), “[...] os direitos humanos não são um dado, mas um construído, uma invenção humana, em constante processo de construção e reconstrução". Assim, “[...] não existem direitos fundamentais por natureza. O que parece fundamental numa época histórica e numa determinada civilização não é fundamental em outras épocas e em outras culturas.” (BOBBIO, 2004, p. 38).

Se é inegável o desenvolvimento dos direitos humanos no plano internacional a partir do fim da segunda guerra mundial (MORAVCSIK, 2000), é igualmente inegável que essa ascensão normativa tem sido desafiada por certo ceticismo (KENNEDY, 2002), sobretudo no que concerne às teorias que buscam explicar o que são os direitos humanos.

Um dos autores que se apropriam desse debate é Charles Beitz, que desafia a abordagem mais convencional de outros estudos, ao utilizar a história e a aplicação política dos direitos humanos como métodos de análise da sua gênese. Assim, ele retira suas premissas da prática política internacional ao invés de partir de princípios abstratos amparados na ideia de natureza humana. Segundo Beitz, os direitos humanos têm se desenvolvido em várias frentes: no direito internacional, em instituições glo- 
bais e regionais, nas políticas externas dos países (principalmente liberal democrático), e nas atividades de um conjunto diversificado e crescente de organizações não-governamentais $(\mathrm{ONG})$. A prática tornou-se politicamente mais visível desde o fim da Guerra Fria, à medida que a doutrina dos direitos humanos foi se expandido e os recursos humanos, políticos e materiais dedicado à proteção e promoção dos direitos humanos se multiplicaram (BEITZ, 2009, p. 2).

Ao analisar as abordagens teóricas que procuram responder ao questionamento do que seriam direitos humanos, Beitz (2009, p. 49) critica as teorias naturalistas, para as quais direitos humanos partiriam de direitos naturais pretéritos. Esta perspectiva ortodoxa aposta na origem transcendental destes direitos (fundada na natureza, em Deus ou na razão) e defendem que eles "[...] são um dado, derivando tão somente do fato de alguém ser um ser humano" (DAMBOUR, 2010, p. 2). Se opondo a essa ideia, Beitz (2009) afirma que os direitos humanos advêm do desenvolvimento de práticas políticas e sociais contemporâneas que servem de "common grounds" para ações políticas de pessoas situadas em culturas diferentes, com tradições diferentes.

Assim, para Beitz (2009, p. 102), os direitos humanos são discursos críticos que guiam a ação política internacional. É importante considerar que, para o autor, a falta de consenso geral sobre essas práticas não nega a existência de ações no sentido de resguardar esses direitos. O elemento essencial para ele é a visão de que os direitos humanos são uma construção social. O grande diferencial dessa concepção é a de que ela considera o papel desempenhado pelos direitos humanos tanto no discurso quanto na prática.

Para construir a sua alternativa teórica, Charles Beitz parte de John Rawls e seu Direito dos Povos, de onde ele irá retirar as bases de sua teoria. Nesse sentido, para Beitz existiria uma Sociedade dos Povos caracterizada por uma comunidade discursiva global que produz consensos materiais acerca do que devem ser os direitos humanos. Participa desta deliberação um grupo heterogêneo de agentes, incluindo governos estatais, organismos internacionais, advogados e legisladores internacionais, agentes econômicos, organismos não governamentais e participantes em 
redes internas e transnacionais e movimentos políticos sociais (BEITZ, 2009, p. 8).

Para Beitz, a prática de direitos humanos na esfera política internacional, e não a sua eventual fundamentação moral, teve e tem um papel importante na sua constante construção. Essa ideia prescindiria de qualquer concepção filosófica sobre a natureza e as bases dos direitos humanos. De acordo com a prática internacional, os direitos humanos seriam o nome de uma empresa internacional composta por um conjunto de regras para a regulação do comportamento de uma classe de agentes, uma crença mais ou menos generalizado de que essas regras devem ser respeitadas, e algumas instituições, quase-instituições e processos informais para a sua propagação e implementação (BEITZ, 2009, p. 42).

Para esse autor, os direitos humanos não se configurariam como um regime internacional, mas sim como uma prática emergente, um verdadeiro costume internacional. Ele justifica essa posição com base em Stephen Krasner (1983), uma vez que em comparação com regimes internacionais estabelecidos, como o comércio ou as finanças, os direitos humanos não disporiam de capacidades institucionais para a resolução de conflitos sobre a aplicação de suas normas a casos individuais e para a aplicação de sanções a agentes que não obedecem às interpretações authoritative dessas normas. Segundo Beitz (2009, p. 3), o sistema de direitos humanos ainda se caracterizaria pela fraqueza e assimetrias de suas capacidades de cumprimento das normas. Esse desafio político tem sido analisado recentemente por inúmeras politólogas como Emilie Hafner-Burton (2013), que, através de estudos empíricos, constata que, em que pese os países sejam bons em assinar tratados (política do open doors), são ruins em honrar seus compromissos. No entanto ela verifica que a adesão aos tratados de direitos humanos altera o "custo político" das violações dos pelos Estados (HAFNER-BURTON, 2013, p. 80).

Qual a diferença entre a concepção de Comparato que considera os direitos humanos uma expressão institucional de um cosmopolitismo moral e a compreensão dos direitos humanos como uma prática internacional emergente, tal como Beitz? A diferença não está no fundamento, mas antes disso, está em que a primeira posição necessita de um fundamento 
último - moral - para a explicação dos direitos humanos, sendo que a segunda posição, "realista", dispensa o fundamento e se centra na "prática da política internacional" para justificar os direitos humanos.

$\mathrm{Na}$ concepção teórica de Beitz, existem três elementos extraídos da prática política internacional a serem considerados na definição do discurso de direitos humanos. Esses seriam os elementos pelos quais se poderia falar verdadeiramente na existência de uma prática de direitos humanos. O primeiro elemento diz que direitos humanos são normas constitutivas de uma prática global cujo objetivo é proteger indivíduos contra ameaças aos seus interesses mais importantes, provenientes das ações e das omissões dos seus governos (BEITZ, 2009, p. 197).

O segundo elemento indica que a proteção dos direitos humanos deve ser feita primeiramente pelas instituições políticas dos Estados, no que ele chama de primeiro nível de proteção dos direitos humanos. Já o último elemento aduz que direitos humanos são objeto de preocupação internacional, assegurando a ação adequada de agentes externos quando os Estados falham em suas responsabilidades de "primeiro nível" (BEITZ, 2009, p. 114). Os direitos humanos são questões de interesse internacional quando se legitima que agentes externos possam agir quando os Estados falham em suas responsabilidades de "primeiro nível".

Permeia essa posição o forte papel dos Estados na definição dos direitos humanos e na sua promoção. Aqui fica claro o caráter estatocêntrico do modelo de Beitz, embora ele não negue a existência e importância de outros atores não estatais. Ora, ao discutir a normatividade de sua teoria, Beitz traz conceitos de Sociedade Anárquica, de Hedley Bull, para ressaltar que são os Estados que estabelecem as normas que definem a esfera de autonomia dos próprios Estados. Mas essas normas também servem para regulação dos agentes não estatais e indivíduos e, por vezes, funcionam como base para críticas e até sanções advindas da sociedade internacional. Nessa perspectiva da normatividade, Beitz pondera que os direitos humanos são guias para ações em casos de violação, mas as formas de ação e a intensidade delas dependem do contexto (BEITZ, 2009, p. 13). 
Nessa esteira da busca por um fundamento pós-metafísico para os direitos humanos, a obra de Beitz se encontra com a de Joaquim Herrera Flores (2009, p. 13). Segundo esse autor, os direitos humanos e os direitos fundamentais, em seu fundamento pós-metafísico, decorrem dos processos de lutas pelo acesso igualitário aos bens materiais e imateriais e a uma vida digna. $\mathrm{O}$ fundamento último se resume à vida, em sua integridade e dignidade. Assim entendidos, os direitos humanos seriam transitórios (no sentido de não serem absolutos) e nunca plenamente alcançados, mas legitimados em função dos resultados provisórios das lutas sociais e políticas pela dignidade humana (RAJAGOPAL, 2005).

Os direitos humanos são, assim, “[...] um produto cultural surgido em um contexto concreto e preciso de relações que começa a expandir-se por todo o globo - desde o século XV até estes incertos inícios do século XXI - sob o nome de modernidade ocidental capitalista" (HERRERA FLORES, 2009, p. 3). Nesse ínterim, mais importante que identificar elementos racionais para embasar os direitos humanos, é necessário reconhecer a potência desse discurso na efetivação desses direitos, tanto interna quanto internacionalmente (POZZATTI; HAAG, 2017). A gênese dessa práxis institucional de direitos humanos se deu efetivamente com o estabelecimento da Organização das Nações Unidas ONU, em 1945, e da Declaração Universal de Direitos Humanos, em 1948 (DONNELY, 1984).

Para além da mera promoção, nas décadas de 1960 e 1970, emergiram iniciativas de monitoramento dos direitos humanos. O sistema ONU deixou de se preocupar exclusivamente com o estabelecimento de direitos humanos e passou a monitorá-los, já que a existência de normas internacionais não implica, por si só, às Nações Unidas, ou qualquer outra pessoa, a autoridade para implementá-las, ou mesmo para investigar como os Estados os implementam (ou não os implementam) (DONNELY, 1984).

A ratificação dos Pactos de 1966 (um para tutelar os direitos civis e políticos e outro os direitos econômicos, sociais e culturais), que entraram em vigor dez anos mais tarde, significou a anuência dos Estados em caminhar conforme os padrões internacionais de direitos humanos estabe- 
lecidos, mas eles ainda não autorizavam a execução internacional desses direitos.

Ainda que com dificuldade de avançar no sentido do enforcement, o Sistema ONU de Direitos Humanos caminhou na década de oitenta rumo a um aumento da sua institucionalização (SIMMONS, 2009). A realização de diversas convenções temáticas, tais como a da mulher, da tortura, do direito ao desenvolvimento e da criança é uma manifestação clara dessa institucionalização. Em 1993, na Conferência de Direitos Humanos de Viena, houve a criação do Alto Comissariado da ONU para Direitos Humanos, demonstrando que o Sistema ONU buscava expandir sua capacidade de monitoramento.

Vale ressaltar que, em que pese os Estados tenham demonstrado grande interesse na construção do discurso dos direitos humanos e continuam sendo os responsáveis pela sua aplicação no plano doméstico, eles também se portam como os grandes violadores dos direitos dos seus cidadãos (KENNEDY, 2002). Nessa perspectiva realista, os direitos humanos não deveriam ser respeitados pelos seus fundamentos morais, mas simplesmente pela sua materialidade empírica, pelo consenso em que se transformaram nos últimos 60 anos. E justamente a partir dessa materialidade, os direitos humanos se transformaram em verdadeiros critérios de legitimação das ordens jurídicas particulares.

Assim, o dever de cooperação internacional pode ser justificado no âmbito dos direitos humanos, senão porque ela seria uma decorrência do princípio ético da solidariedade, tão somente porque existe uma série de tratados internacionais que positivou tal dever. Ora, quando tratados internacionais são firmados, eles trazem para o âmbito do direito os projetos de cooperação. Isso implica reconhecer a juridificação das políticas públicas internacionais e da própria cooperação.

\section{Conclusão}

Para responder à pergunta "existe um dever de cooperação internacional?", a presente pesquisa realizou a uma abordagem normativa do tema capaz de fundamentar tal dever. Nessa empreitada, buscou-se na te- 
oria dos direitos humanos uma compreensão do princípio da solidariedade que permitiu compreender o conteúdo material do discurso da cooperação internacional, o que permitiu concluir que a cooperação exerce a função de ser um meio para a efetivação de direitos.

Para tanto, na primeira parte foi investigado a maneira com que o conceito de direitos humanos se entrelaça com a ideia de cooperação internacional. A partir da investigação do desenvolvimento das bases dos direitos humanos, foi possível apresentar a relação entre cooperação internacional e direitos humanos em três perspectivas conceituais, seja ontologicamente, seja deontologicamente ou ainda na dimensão da práxis. Isso quer dizer que essa relação pode ser fundada tanto na definição de direitos humanos - como os direitos humanos são universais, indissociáveis e interdependentes, a ideia de cooperação internacional faz parte da sua própria definição - como em um dever - como os direitos humanos existem em "todos" os lugares, eles devem ser efetivados em todos os lugares.

Na segunda parte, discutiu-se as possibilidades e aporias de uma fundamentação para os direitos humanos. Nesse momento, apontou-se tanto para uma fundamentação moral dos direitos humanos no princípio ético da solidariedade, a partir do idealismo transcendental de matriz kantiana, quanto para uma fundamentação jurídico-política dos direitos humanos, em que eles são valores políticos que as sociedades liberais decidem acordar.

A partir dessa dupla ótica apresentada, conclui-se pela constatação de uma dupla possibilidade de afirmação de um dever de cooperação internacional, tanto na perspectiva moral, como na jurídica. Se os direitos humanos forem considerados na primeira perspectiva, é possível afirmar um dever de cooperação internacional de ordem moral. Entretanto, se forem considerados os direitos humanos na segunda ótica, da juridicidade, o dever de cooperação internacional deve ser procurado na própria legislação. Além disso, verificou-se que o dever de cooperação internacional ganha lastro na perspectiva pós-metafísica dos direitos humanos.

Desde 1948, a prática do direito internacional dos direitos humanos alcançou muitos resultados: estabeleceu entendimentos compartilhados do que é aceito e o que não é na comunidade internacional; construiu sis- 
temas de coerção para incentivar bons comportamentos e punir os maus e melhorou no entendimento de como alterar o "custo político" das violações de direitos humanos pelos Estados. Mas tem muitos desafios, como modificar culturas políticas locais e práticas sociais, e esse processo passa pelo entendimento da cooperação como um dever.

\section{Referências}

ALEXY, Robert. Teoría de los derechos fundamentales. Madrid: Centro de Estudios Constitucionales, 1997.

ARENDT, Hannah. As origens do totalitarismo. Tradução de Roberto Raposo. São Paulo: Companhia das Letras, 1998.

BEITZ, Charles. The Idea of Human Rights. Oxford: University Press, 2009.

BOBBIO, Norberto. A era dos direitos. Tradução de Regina Lyra. Rio de Janeiro: Elsevier; Campus, 2004.

CASTELLS, Manuel. A Sociedade em Rede: do Conhecimento à Política. In: CASTELLS, Manuel; CARDOSO, Gustavo (org.). A Sociedade em Rede do Conhecimento à Acção Política. Lisboa, PT: Imprensa Nacional - Casa da Moeda, 2005. p. 17-30.

COMPARATO, Fabio Konder. A afirmação histórica dos direitos humanos. São Paulo: Saraiva, 2001.

COMPARATO, Fabio Konder. Ética: direito, moral e religião no mundo moderno. São Paulo: Companhia das Letras, 2006.

DEMBOUR, Marie-Bénédicte. What Are Human Rights? Four Schools of ought. Human Rights Quarterly, [S.l.], v. 32, n. 1, p. 1-20, February 2010.

DELMAS-MARTY, Mireille. Les forces imaginatives du droit (I): Le pluralisme ordonné. Paris: Seuil, 2006.

DONNELLY, Jack. Cultural Relativism and Universal Human Rights. Human Rights Quarterly, [S.l.], v. 6, n. 4, p. 400-419, 1984. 
HABERMAS, Jürgen. A constelação pós-nacional: ensaios políticos. Tradução de Márcio Seligmann-Silva. São Paulo: Litera Mundi, 2001. HABERMAS, Jürgen. Direito e democracia: entre faticidade e validade. Rio de Janeiro: Tempo Brasileiro, 1997. v. 1.

HABERMAS, Jürgen. La inclusión del otro: estudios de Teoría Política. Tradução de Juan Carlos Velasco. Barcelona: Paidós, 2012a.

HABERMAS, Jürgen. Sobre a constituição da Europa: um ensaio. São Paulo: Ed. Unesp, 2012b.

HABERMAS, Jürgen. Plea for a constitutionalization of international law. Philosophy and Social Criticism, [S.l.], v. 40, 2014.

HAFNER-BURTON, Emilie. Making Human Rights a Reality. Princeton: University Press, 2013.

HERRERA FLORES, Joaquín. Teoria crítica dos direitos humanos: os direitos humanos como produtos culturais. Trad. por Luciana Caplan et al. Rio de Janeiro: Lumen Juris, 2009.

JOUANNET, Emmanuelle. Qu'est-ce qu'une société internationale juste? Paris: Pedone, 2012.

KELSEN, Hans. The law of the United Nations: a critical analysis of its fundamental problems. London: Stevens, 1950.

KENNEDY, David. The international human rights movement: part of a problem? Harvard Human Rights Journal, [S.l.], v. 15, 2002.

KOSKENNIEMI, Martti. The Gentle Civilizer of Nations: the Rise and Fall of International Law 1870-1960. New York: Cambridge University Press, 2001.

KRASNER, Stephen. International regimes. Ithaca: Cornell University Press, 1983.

LAFER, Celso. A reconstrução dos direitos humanos: um diálogo com o pensamento de Hannah Arendt. São Paulo: Companhia das Letras, 1988. 
MORAVCSIK, Andrew. The origins of Human Rights Regimes. International Organizations, [S.l.], v. 54, n. 2, p. 217-252, 2000.

PINZANI, Alessandro. A cara de Janus dos direitos humanos: o direito humano entre a política e a moral. In: LUNARDI, Govani; SECCO, Márcio (org.). Fundamentação Filosófica dos Direitos Humanos. Florianópolis: Editora da UFSC, 2010. p. 25-48

POZZATTI, Ademar; HAAG, Valentina. Da transcendência à imenência: a teoria critica como alternativa epistemologica a ineficacia dos direitos humanos. Revista Direito e Politica do PPGD Univali, [S.l.], v. 12, n. 3, p. 1.449-1.487, 2017.

POZZATTI, Ademar. ¿Existe un fundamento para afirmar un deber de cooperación internacional? Ensayo sobre el derecho internacional en el marco de la ética práctica kantiana. Anuario Mexicano de Derecho Internacional, [S.l.], v. XVII, p. 591-622, 2017.

RAJAGOPAL, Balakrishnan. EI derecho internacional desde abajo: el desarollo, los movimentos sociales y la resistência del Tercer Mundo. Bogotá: ILSA, 2005.

RAMOS, André de Carvalho. Teoria Geral dos Direitos Humanos na Ordem Internacional. Rio de Janeiro: Renovar, 2005.

SIMMONS, Beth. Mobilizing for Human Rights: International Law in Domestic Politics. Cambridge: University Press, 2009.

TORRONTEGUY, Marco Aurélio Antas. O direito humano à saúde no direito internacional: efetivação por meio da cooperação sanitária. 2010. 355 p. Tese (Doutorado) - Faculdade de Direito da USP, São Paulo, 2010.

WOLFRUM, Rüdiger. International law of cooperation: Encyclopedia of Public International Law. Amsterdam: North-Holand, 1986.

Ademar Pozzatti Junior é professor adjunto de Direito Internacional na Universidade Federal de Santa Maria (UFSM), onde coordena o Núcleo de 
Pesquisa e Práticas em Direito Internacional (NPPDI). Possui Mestrado e Doutorado pelo Programa de Pós-Graduação em Direito da Universidade Federal de Santa Catarina (UFSC/Brasil), com estágio de pesquisa junto à École de Droit do Institut d'Estudes Politiques de Paris (Sciences Po/França).

E-mail: ademar.pozzatti@ufsm.br

Endereço profissional: Av. Roraima, n. 1.000, Camobi, Santa Maria, RS. CEP: 97105-900. 